\title{
Social support and maternal stress during pregnancy: a PATH model
}

\author{
Sara Shishehgar ${ }^{* 1}$, Mahrokh Dolatian², Hamid Alavi Majd ${ }^{3}$, Zohre Teimouri ${ }^{2}$, Seyedeh Tahoora Alavi ${ }^{4}$, Parivash \\ Halvaei $^{5}$ \\ ${ }^{1}$ Faculty of Health, University of Technology, Sydney, Australia \\ ${ }^{2}$ School of Nursing and Midwifery, Shahid Beheshti University of Medical Sciences, Tehran, Iran \\ ${ }^{3}$ Department of Biostatistics, School of Paramedical Sciences, Shahid Beheshti University of Medical Sciences, Tehran, Iran \\ ${ }^{4}$ School of general psychology, Qazvin University, Qazvin, Iran \\ ${ }^{5}$ Azad university of Tehran-North, Iran
}

Received: June 15, 2015

DOI: $10.5430 /$ ijh.v2n1p44
Accepted: October 11, $2015 \quad$ Online Published: November 2, 2015

URL: http://dx.doi.org/10.5430/ijh.v2n1p44

\begin{abstract}
Background: Lack of appropriate social support and resultant increased maternal stress during pregnancy contributes to negative pregnancy outcomes for both mothers and the future offspring.

Objective: The primary aim of this study was to investigate the relationship between social support and maternal stress during pregnancy.

Methods: This descriptive-correlative study was conducted on 210 pregnant women who met inclusion criteria and attended Shahryar Social Security Hospital from August to December 2012. Participants were recruited through a purposive convenient sampling. Questionnaires about socio-economic status, the Vaux Social Support Record and pregnancy-specific stress were completed by participants. SPSS-19 and Lisrel 8.8 were used for data and path analysis.

Results: There was a significant relationship between perceived social support and maternal stress $(p<.05)$; however, support from family members and partners had the most affect. An emergent path model fitted $(\mathrm{CF} 1=1, \mathrm{RMSEA}=0.00)$ and, accordingly, direct social support $(t$-value $=7.3$ ) influenced maternal stress during pregnancy. But socio-economic status did not show significant impact.

Conclusions: Since social support is a measurable and multi-dimensional factor, health managers and policy makers ought to assess, recognize and apply specific support resources for pregnant women. Our data also support the idea that empowering family members and partners to support pregnant women by involving them in prenatal care programs is important to reduce maternal stress rate.
\end{abstract}

Key Words: Path model, Pregnancy, Social support, Stress

\section{INTRODUCTION}

Pregnancy is an extensive life event which most healthy women adjust to well, both physically and regarding psychological changes; however, some experience high levels
Although there has been an extensive improvement in the physical health care of pregnant women in health services, psychological care is still overlooked. ${ }^{[2]}$ Maternal stress is defined as an emotional state that has been neglected by obstetric medicine. ${ }^{[3]}$ Inability to cope with psychological

\footnotetext{
*Correspondence: Sara Shishehgar; Email: Sara.shishehgar-1@ student.uts.edu.au; Address: Faculty of Health, University of Technology, Sydney,
} Australia. 
changes may result in adverse physical and mental outcomes for both mothers and children. ${ }^{[4]}$

Pregnancy-specific stress is defined as a concern about pregnancy process, childbirth, infant health and pregnancy outcomes. ${ }^{[5]}$ Stress may be linked to some adverse outcomes such as preeclampsia, abortion, suppressing the immune system, and nausea for mothers as well as low birth weight for infants. ${ }^{[6-9]}$ Hyperactivity and behavioral issues for children of school age, moreover, could be the results of high burden of pregnancy stress. ${ }^{[10]}$

Apart from physical outcomes, psychological disorders such as prenatal and post-natal depression are strongly predictable within women who suffer from high levels of stress. ${ }^{[1-14]}$ Seemingly, schizophrenia among male offspring is proposed and related to some maternal stress during pregnancy in literature. $^{[8,15,16]}$

Importantly, social support and quality of life are recognized as buffering factors that decrease both stress level and adverse effects of stress on either the mother and/or infant. ${ }^{[7,11,17-20]}$ Social networking makes a person feel confident and valued and enhances the chance of having healthy mothers and babies. $^{[21]}$ With respect to negative impacts of lack of social support on people's health, ${ }^{[22]}$ many experts represent prenatal and post-natal dyspnea, digestive problems, and depression as the results of social isolation. ${ }^{[21,23]}$ However, sexual partner's support seems to mitigate chronic stress effects on maternal and neonatal outcomes. ${ }^{[24]}$ Although pregnancy stress has been investigated in previous studies, it continues as a persistent problem ${ }^{[14,25]}$ with few well defined solutions and interventions offered in the literature. Health care services may be the optimal first line of redress to help pregnant women suffering from the short and/or long-term consequences of maternal stress. ${ }^{[26]}$ Prevalence of maternal stress has been reported 33\%-37\% and 5\%-7\% in England and Sweden, respectively. ${ }^{[27]}$ This rate is also estimated to about $16.7 \%$ and $13.6 \%$ for severe and mild pregnancy stress, respectively, amongst Iranian women. ${ }^{[28]}$

Given the potential buffering effects of social support on maternal stress and improving pregnancy outcomes on the one hand, and shortage of relevant studies in Iran, on the other hand, this study was performed to investigate the relationship of social support and maternal stress level among Iranian pregnant women. In this study we used the term maternal stress to define stress which occurs during pregnancy.

\section{Methodology}

This cross-sectional descriptive-correlative study was performed from August to December, 2012. Shahryar Hospital located in west of Tehran, Iran, was the research setting.
A purposeful convenient sampling method was applied to reach the required sample size that was estimated at 210 participants using the correlation formula shown (see Figure 1).

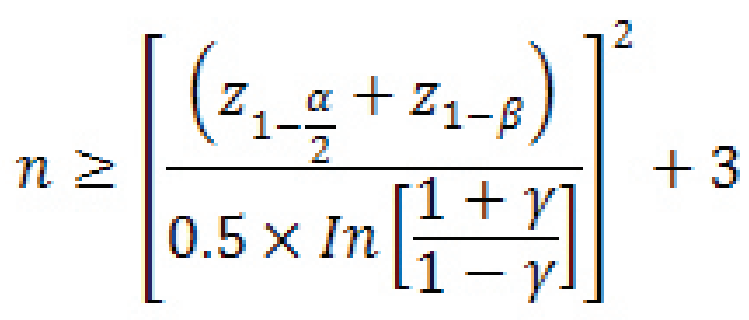

Figure 1. Correlation formula

According to previous similar studies, suitable amount for $\gamma$ was 0.2 , for $\alpha$ was 0.05 and for $\beta$ was 0.2. 196 participants were estimated by the statistician. Given the probability of missing data, we decided to recruit 210 participants including 70 participants in each trimester.

\subsection{Participants}

All pregnant women who met the inclusion criteria and attended Shahryar Hospital for scheduled prenatal care during the study period were invited to participate in this study.

Selected women must be in their first or second pregnancy, with a single fetus. They must not have a disabled husband or child, and no experience of a major life issue during the last 6 month. Non-smokers and non-drug users were considered as potential participants. Women who met the inclusion criteria were given an information sheet and an informed consent form. All participants were informed about the aims of study and assured that their information will be confidential. They also were informed that their participation is completely voluntary and they can withdraw at any time they wish. Furthermore, participants were noted that there is no financial reward for their participation in this study. They also were told that there are no direct benefits or risks for participating in this study. Ethics approval was obtained from the Shahid Beheshti University and the clinical setting where the study was undertaken.

\subsection{Data collection}

After agreement to participate, each woman completed three distinct questionnaires including pregnancy stress, modified social support Vaux (SS-A), and socio-economic questionnaires. Socio-economic characteristics included age and occupation of the participants and their husbands, marital status, family income, education level, living area, recreational facilities and leisure activities. The correlation of all parameters was found to be 0.87 . Factor analysis and a summary 
index were used for calculating the total standardized score. Kappa test was used to assess questionnaire compliance with a normal summary index. The potential maximum score, consequently, was 46 marks. ${ }^{[29]}$

Social support questionnaire (VAUX) was a 23-item scale. The questions centered on perceived support from family members focusing on the partner with 8 questions, friends with 7 questions and other people with 8 questions. Examples for various domains include "my family members respect me" for family domain, "I can rely on my friends" for friends domain and "people admire me" for other people domain. Each question was answered using a 5-point Likert scale from strongly disagree to strongly agree. Scores were then calculated separately for each domain; and for overall social support. Scores of 18 and above represented appropriate social support. Validity and reliability of this instrument have been determined through content validity and Cronbach's alpha $0.7-0.9$ by previous studies. ${ }^{[30]}$

Maternal stress was calculated by the specific pregnancy stress questionnaire. Survey questions investigated broad areas of stress during pregnancy in six domains including health, personal and family, environmental, financial, religion, and perception of others about the participant's appearance. Questions in various domains are; "I worry about preterm labor" for health domain; "I worry about others' opinion about my appearance" for perception of others domain; "I worry about presence of men in birth room" for religion domain; "I worry about the expenses of hospital" for financial domain; "I am scared of labor ward" for environmental domain; and "I worry about my kid's gender" for family and personal domain. 51 questions in all domains were answered from 0 for no stress to 4 for very high stress. Sum of the scores, then, were rated between 0-100 percent and categorized into three levels: mild, average, severe stress. Validity and reliability of this questionnaire were calculated in previous studies using test-retest and Cronbach's alpha coefficient $=0.75{ }^{[28]}$

\subsection{Data analysis}

This Study was based on an integrative conceptual framework presented by Billings and Moos in 1982. [31] A part of the framework indicates a direct path for perceived social support and socio-economic status (SES) and stress and mental disorder rate (see Figure 2). Path analysis helps rationalize the observed relationship through demonstrating direct and indirect effects of independent variables on dependents.

The Statistical Package for the Social Sciences version 19 (SPSS 19) was used to analyze the collected data. Normality of data was determined before data analysis. The relationship between overall social support and its domains with maternal stress level was analyzed using Chi-square. To demonstrate the exact correlation between variables, Pearson test was applied. $p<.05$ was considered as a significant level statistically. Path analysis was done using Lisrel 8.8 software. The rationale to doing a path analysis was the intention to explore both direct and indirect effects of perceived social support and SES on maternal stress during pregnancy.

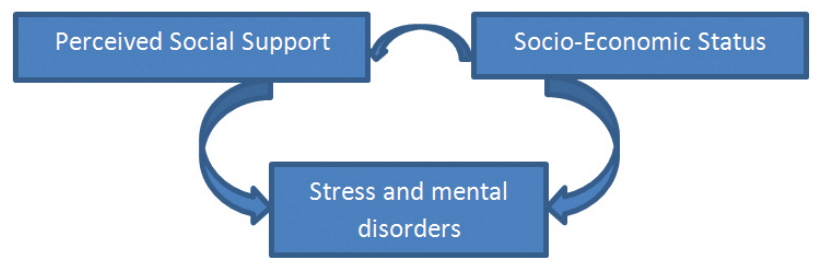

Figure 2. Billings and Moos modified conceptual framework

\section{Results}

Of 210 pregnant women who met inclusion criteria were interviewed face-to-face by the first author. Mean age of participants was $29 \pm 4.8$ years. The majority of participants were housewives $(89 \%)$, urban residents $(90.5 \%)$ and low income $(77.6 \%)$ (see Table 1$)$.

Table 1. Demographic information of pregnant women $(\mathrm{N}=210)$ attending Shahryar hospital

\begin{tabular}{|c|c|c|}
\hline Variables & $N=210(\%)$ & Mean \pm SD \\
\hline Age, Years & & $29 \pm 4.8$ \\
\hline$<30$ & $160(76.1)$ & \\
\hline$>30$ & $50(23.9)$ & \\
\hline \multicolumn{3}{|l|}{ Education } \\
\hline Less than high school & $113(51.4)$ & \\
\hline More than high school & $97(48.6)$ & \\
\hline \multicolumn{3}{|l|}{ Husband Education } \\
\hline Less than high school & $128(61)$ & \\
\hline More than high school & 82(39) & \\
\hline \multicolumn{3}{|l|}{ Occupation } \\
\hline Housewife & 188(89) & \\
\hline Employed & $22(11)$ & \\
\hline \multicolumn{3}{|l|}{ Husband Occupation } \\
\hline Low class job & $26(12.4)$ & \\
\hline Medium class job & $144(68.6)$ & \\
\hline High class job & $40(19)$ & \\
\hline \multicolumn{3}{|l|}{ Income } \\
\hline Low Income & 163(77.6) & \\
\hline High Income & $47(22.4)$ & \\
\hline \multicolumn{3}{|l|}{ Residential Area } \\
\hline City & 190(90.5) & \\
\hline Rural & $20(9.5)$ & \\
\hline
\end{tabular}

According to the achieved mean scores for social support 
$(17.2 \pm 3)$ and stress $(43.6 \pm 20.1)$, the participants perceive relatively good social support and their maternal stress level are within an average rate. A significant relationship was observed between perceived social support, SES and maternal stress level during pregnancy $(p<.05)$. In addition, an inverse significant correlation was observed between perceived social support and maternal stress $(r=-0.039)$ (see Table 2$)$.

Table 2. Correlation and relationship between social support and stress during pregnancy

\begin{tabular}{|c|c|c|c|c|c|c|}
\hline Variables & & Mild Stress N = 68 & Moderate Stress N = 116 & Severe Stress N = 26 & Chi-Square & Correlation \\
\hline \multirow{2}{*}{ Social Support } & Appropriate & $38(55.88 \%)$ & $61(52.59 \%)$ & $13(50 \%)$ & \multirow{2}{*}{0.000} & \multirow{2}{*}{-0.039} \\
\hline & Inappropriate & $30(44.12 \%)$ & 55 (47.41\%) & $13(50 \%)$ & & \\
\hline \multirow{2}{*}{$\begin{array}{l}\text { Socio-economic } \\
\text { Status }\end{array}$} & Appropriate & 50 (73.53\%) & $94(81 \%)$ & $21(80.8 \%)$ & \multirow{2}{*}{0.000} & \multirow{2}{*}{$>0.05$} \\
\hline & Inappropriate & 18 (26.47\%) & 22 (19\%) & $5(19.2 \%)$ & & \\
\hline
\end{tabular}

To investigate the model fitness, CFI, GFI and RMSEA were used. According to the conceptual model, the current model was a fit, desirable and rationalized model without significant difference (see Table 3).

Table 3. Goodness of fit indices for the model

\begin{tabular}{lllllll}
\hline & $\chi^{2}$ & Df & P & GFI & CFI & RMSEA \\
\hline Model Index, $\mathrm{n}=210$ & 0.44 & 1 & 0.51 & 1 & 1 & 0.000 \\
\hline
\end{tabular}

According to the path diagram, social support $(\beta=-0.2)$ had a direct effect on maternal stress. This model illustrated that appropriate social support has a lowering effect on maternal stress while low social support, significantly, increases stress and resultant adverse outcomes during and after pregnancy (see Table 4). Surprisingly, family members were found as the most influential resource of social support that could decrease maternal stress significantly. Although it was expected to see a significant path for SES and maternal stress, according to Billing and Moos conceptual framework, this study failed to find that (see Figure 3).

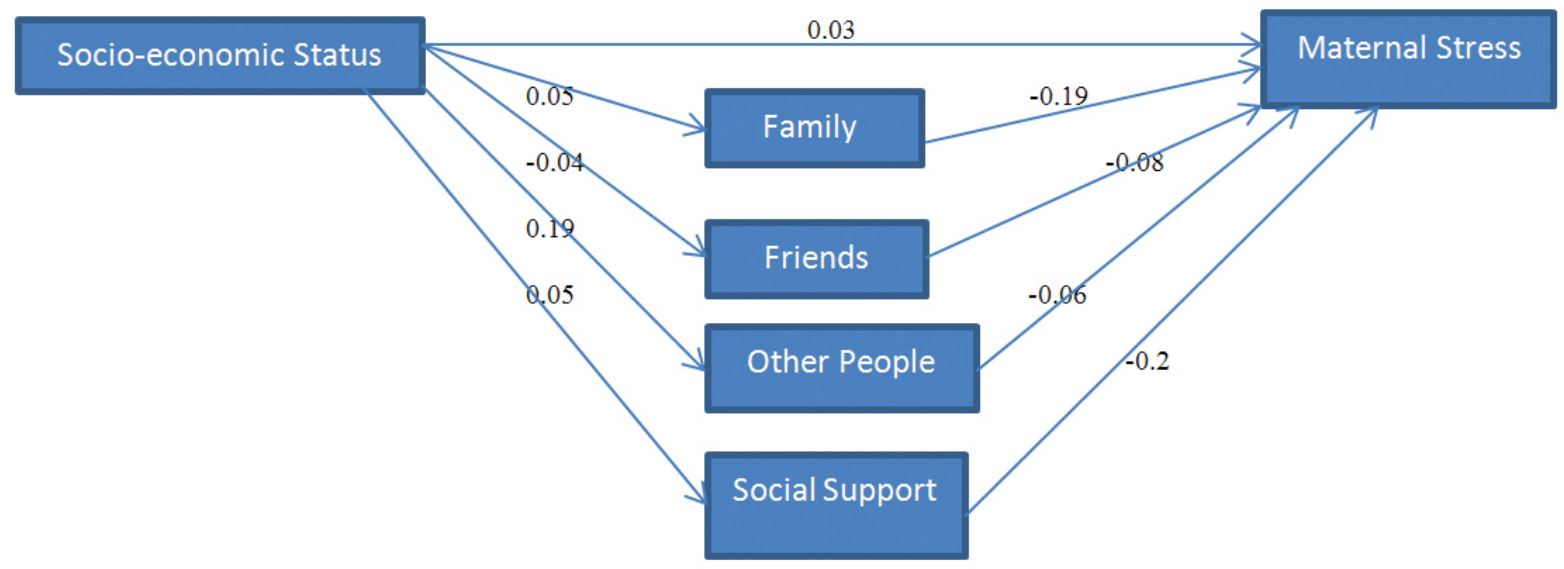

Figure 3. Full path model (Empirical path model for relationship of social support and socio-economic status with maternal stress)

The revealed regression coefficients, moreover, are standard and affirm the achieved paths for social support and SES and Published by Sciedu Press maternal stress. Social support, obviously, is more effective than SES on stress during pregnancy (see Table 4). 
Table 4. Path coefficients for social support, socio-economic status and maternal stress

\begin{tabular}{llllll}
\hline \multirow{2}{*}{ Predictor Variables } & \multicolumn{3}{c}{ Effects } & \multirow{2}{*}{ Model Coefficients } & \multirow{2}{*}{ value } \\
\cline { 2 - 5 } & Direct & Indirect & Total & 7.69 & 7.3 \\
\hline Social Support & -0.2 & $-0.05^{*}$ & -0.25 & 0.26 & 2.1 \\
Socio-Economic Status & $0.03^{*}$ & $0.024^{*}$ & 0.054 & \\
\hline
\end{tabular}

* No significant

\section{Discussion}

In this study, efforts were made to demonstrate the relationship between maternal stress as a psychological issue and perceived social support during pregnancy. SES was also considered in this study as a factor which was expected to influence maternal stress rate. Expectedly, perceived social support had a significant relationship with maternal stress ( $p$ $<.05)$. This study mirrors results of previous studies examining the most important resources of support for pregnant women. ${ }^{[24,32]}$ This study, indeed, supported the assumption that stressful events and their adverse effects may be moderated by supportive factors like support from immediate family members and in particular partners but this relationship is lower for friends and other people generally. Since most of the questions investigated women's stress about hospitalization, the delivery process and hospital staff's behaviors, friends and other people generally may be not able to reduce these kinds of stressors. Thus, investigations into other aspects of support from such persons, including functional/practical and emotional support ought to be considered for future studies.

The empirical path model indicates that the path of social support that decreases maternal stress level the most, is through the family domain $(\beta=-0.19)$. This shows that the better support from family members and the partner, the lower stress during pregnancy, while friends and others have less impact. SES, on the other side, had no significant relationship with stress either directly or indirectly through the path of social support. Further studies with more participants may find a significant relationship.

Results of this study may be supported by a biological explanation. Ditzen et al. emphasized a strong inverse correlation between social support and stress rate. Appropriate social support reduces anxiety and stress through blood cortisol reductions (cortisol is a stress hormone that activates a stress response, including elevated heart rate, pulse, perspiration, etc.). ${ }^{[33]}$

Social support during pregnancy is measurable, and given its direct effect on decreasing adverse pregnancy outcomes by reducing maternal stress, its measurement would be worthy for policy makers and healthcare organizations for planning care for pregnant women and their babies. Since pregnant women with appropriate support resources, despite high burden of stress, have fewer complications, arranging counseling sessions to involve partners in prenatal care and delivery process may contribute to lower stress as well as healthier mothers and babies. ${ }^{[20,34]}$ One focus of such counseling may be on how to help coach a relaxation response in their pregnant partner and/or how to remove unnecessary/burdensome stressors from her overall life situation. Since the main aim of this study was to investigate the relation between social support and specific-pregnancy stress, women experiencing severe stressors such as missing a close family member were excluded from this study. This exclusion is a limitation of this study which may not permit the results to be generalized to many women who have had profound, recent stressful life events.

\subsection{Limitations}

The nature of this quantitative study has some limitations. Women's feelings about their stressors, resources and perceived social support were not explored, for example, and would be good topics for future qualitative studies. In addition, results of cross-sectional studies are completely dependent on the mood of participants at the time of conducting data collection. This fact might influence the results of these kinds of studies. Therefore, conducting further longitudinal studies seems to be worthy to attain more robust and generalizable findings. Finally, the convenience sampling method may have incurred some sampling bias. Recruiting participants through a randomized sampling method is strongly recommended for future studies.

\subsection{Strengths}

In spite of limitations, this study has a number of strengths. First, according to our knowledge, this is a unique study that examined the relationship between social support, socioeconomic status and maternal stress using path model. Presenting a fit model assessing social support and socioeconomic status and their relations with specific-pregnancy stress is an important aspect of this study. Second, consideration of all trimesters of pregnancy makes this study unique since most previous studies focused on only one trimester of pregnancy. ${ }^{[2,35]}$ 


\section{Conclusion}

Generally, this study made all effort to demonstrate a direct and indirect relationship between various domains of social support, socio-economic status and maternal stress. Immediate family members and in particular the partner had the most significant buffering effect on maternal stressors during pregnancy. Since social support is a multi-dimensional and measurable factor, health managers and policy makers might plan for and promote specific support resources for pregnant women. These may include empowering family members and partners to support the pregnant women by involving them in prenatal care programs.

\section{REFERENCES}

[1] Lynn FA, Alderdice FA, Crealey GE, et al. Associations between maternal characteristics and pregnancy-related stress among lowrisk mothers: An observational cross-sectional study. International journal of nursing studies. 2011; 48(5): 620-627. PMID:21087767. http://dx.doi.org/10.1016/j.ijnurstu.2010.10.002

[2] Elsenbruch S, Benson S, Rucke M, et al. Social support during pregnancy:effect on maternal depressive symptoms,smoking and pregnancy outcome. Human Production. 2007; 22(3): 869-877.

[3] Glover V. Maternal depression, anxiety and stress during pregnancy and child outcome; what needs to be done. Best practice \& research Clinical obstetrics \& gynaecology. 2014; 28(1): 25-35. PMID:24090740. http://dx.doi.org/10.1016/j.bpobgyn. 2 013.08 .017

[4] La Marca-Ghaemmaghami P, Ehlert U. Stress During Pregnancy. European Psychologist. 2015. http://dx.doi.org/10.1027/1 016-9040/a000195

[5] Littleton HL, Breitkopf CR, Berenson AB. Correlates of anxiety symptoms during pregnancy and association with perinatal outcomes: a meta-analysis. American journal of obstetrics and gynecology. 2007; 196(5): 424-432. PMID:17466693. http://dx.doi.org/1 $0.1016 / \mathrm{j} \cdot$ ajog. 2007.03 .042

[6] Gray JB. Social Support Communication in Unplanned Pregnancy: Support Types, Messages, Sources, and Timing. Journal of health communication. 2014; 19(10): 1196-1211. PMID:24650349. http: //dx.doi.org/10.1080/10810730.2013.872722

[7] Divney AA, Sipsma H, Gordon D, et al. Depression during pregnancy among young couples: The effect of personal and partner experiences of stressors and the buffering effects of social relationships. Journal of pediatric and adolescent gynecology. 2012; 25(3): 201-207. PMID:22578481. http://dx.doi.org/10.1016/j.jpag. 2012 .02 .003

[8] Bale TL, Baram TZ, Brown AS, et al. Early life programming and neurodevelopmental disorders. Biological psychiatry. 2010; 68(4): 314-319. PMID:20674602. http://dx.doi.org/10.1016/j.b iopsych. 2010.05.028

[9] Bilbo SD, Schwarz JM. Early-life programming of later-life brain and behavior: a critical role for the immune system. Frontiers in behavioral neuroscience. 2009; 3. http://dx.doi.org/10.3389 /neuro.08.014.2009

[10] Loomans E, van der Stelt O, van Eijsden M, et al. Antenatal maternal anxiety is associated with problem behaviour at age five. Early human development. 2011; 87(8): 565-570. PMID:21576004. http://dx.doi.org/10.1016/j.earlhumdev.2011.04.014

[11] Lancaster CA, Gold KJ, Flynn HA, et al. Risk factors for depressive symptoms during pregnancy: a systematic review. American journal of obstetrics and gynecology. 2010; 202(1): 5-14. PMID:20096252. http://dx.doi.org/10.1016/j.ajog. 2009.09.007

[12] Records K, Rice M. Psychosocial correlates of depression symptoms during the third trimester of pregnancy. Journal of Obstetric, Gyneco- logic, \& Neonatal Nursing. 2007; 36(3): 231-242. PMID:17489929. http://dx.doi.org/10.1111/j.1552-6909.2007.00140.x

[13] Zelkowitz P, Schinazi J, Katofsky L, et al. Factors associated with depression in pregnant immigrant women. Transcultural psychiatry. 2004; 41(4): 445-464. PMID:15709645. http://dx .doi .org/10. $1177 / 1363461504047929$

[14] Holzman C, Eyster J, Tiedje LB, et al. A life course perspective on depressive symptoms in mid-pregnancy. Maternal and child health journal. 2006; 10(2): 127-138. PMID:16400535. http://dx.doi .org/10.1007/s10995-005-0044-0

[15] Khashan AS, Abel KM, McNamee R, et al. Higher risk of offspring schizophrenia following antenatal maternal exposure to severe adverse life events. Archives of general psychiatry. 2008; 65(2): 146 PMID:18250252. http://dx.doi.org/10.1001/archgenpsyc hiatry. 2007.20

[16] van Os J, Selten J-P. Prenatal exposure to maternal stress and subsequent schizophrenia. The May 1940 invasion of The Netherlands. The British Journal of Psychiatry. 1998; 172(4): 324-326. PMID:9715334. http://dx.doi.org/10.1192/bjp.172.4.324

[17] Lau Y, Yin L. Maternal, obstetric variables, perceived stress and health-related quality of life among pregnant women in Macao, China. Midwifery. 2011; 27(5): 668-673. PMID:20466467. http: //dx.doi.org/10.1016/j.midw.2010.02.008

[18] Dunkel Schetter C. Psychological science on pregnancy: stress processes, biopsychosocial models, and emerging research issues. Annual review of psychology. 2011; 62: 531-558. PMID:21126184. http://dx.doi.org/10.1146/annurev.psy ch.031809.130727

[19] Da Costa D, Dritsa M, Verreault N, et al. Sleep problems and depressed mood negatively impact health-related quality of life during pregnancy. Archives of women's mental health. 2010; 13(3): 249-257. PMID:19728037. http://dx.doi.org/10.1007/s00 737-009-0104-3

[20] Shishehgar S, Mahmoodi A, Dolatian M, et al. The Relationship of Social Support and Quality of Life with the Level of Stress in Pregnant Women Using the PATH Model. Iranian Red Crescent Medical Journal. 2013; 15(7): 560. PMID:24396574. http: //dx.doi.org/10.5812/ircmj.12174

[21] Elsenbruch S, Benson S, Rücke M, et al. Social support during pregnancy: effects on maternal depressive symptoms, smoking and pregnancy outcome. Human reproduction. 2007; 22(3): 869-877. PMID:17110400. http://dx.doi.org/10.1093/humrep/del4 32

[22] Brummett BH, Mark DB, Siegler IC, et al. Perceived social support as a predictor of mortality in coronary patients: effects of smoking, sedentary behavior, and depressive symptoms. Psychosomatic medicine. 2005; 67(1): 40-45. PMID:15673622. http: //dx.doi.org/10.1097/01.psy.0000149257.74854.b7

[23] Gabbe SG, Niebyl JR, Galan HL, et al. Obstetrics: normal and problem pregnancies. Elsevier Health Sciences; 2012. 
[24] Ghosh JKC, Wilhelm MH, Dunkel-Schetter C, et al. Paternal support and preterm birth, and the moderation of effects of chronic stress: a study in Los Angeles County mothers. Archives of women's mental health. 2010; 13(4): 327-338. PMID:20066551. http://dx.doi.o $\mathrm{rg} / 10.1007 / \mathrm{s} 00737-009-0135-9$

[25] Lumley J, Chamberlain C, Dowswell T, et al. Interventions for promoting smoking cessation during pregnancy. The Cochrane Library. 2009. http://dx.doi .org/10.1002/14651858. cd0010 55. pub3

[26] Kingston D, Heaman M, Fell D, et al. Factors associated with perceived stress and stressful life events in pregnant women: findings from the Canadian Maternity Experiences Survey. Maternal and child health journal. 2012; 16(1): 158-168. PMID:21165763. http://dx.doi.org/10.1007/s10995-010-0732-2

[27] Senturk V, Abas M, Berksun O, et al. Social support and antenatal depression in extended and nuclear family environments in Turkey:across-sectional survey. BMC psychiatry. 2011; 11: 48-58 PMID:21435209. http://dx.doi.org/10.1186/1471-244X-1 $1-48$

[28] Salari P, Firoozi M, Sahebi A. Study of the Stressors Associated with Pregnancy. Journal of Sabzevar University of Medical Sciences. 2005; 12(3): 34-40.

[29] Garmaroudi GR, Moradi A. Socio-economic status in Iran. A study of measurement index. 2010.
[30] Ebrahimi Ghavam S. Relationship between social growth and having social support (with an emphasis on social skills). Unpublished master's thesis, Shahid Chamran University. 1994.

[31] Billings AC, Moos RH. Psychosocial theory and research on depression: An integrative framework and review. Clinical Psychology Review. 1982; 2(2): 213-237. http://dx.doi.org/10.1016/0 272-7358 (82) 90013-7

[32] Negron R, Martin A, Almog M, et al. Social support during the postpartum period: mothers' views on needs, expectations, and mobilization of support. Maternal and child health journal. 2013; 17(4): 616-623. PMID:22581378. http://dx.doi.org/10.1007 /s10995-012-1037-4

[33] Ditzen B, Schmidt S, Strauss B, et al. Adult attachment and social support interact to reduce psychological but not cortisol responses to stress. Journal of psychosomatic research. 2008; 64(5): 479-486. PMID:18440400. http://dx.doi.org/10.1016/j.jpsychore s.2007.11.011

[34] Alipour F, Sajadi H, Forouzan A, et al. The role of social support in the anxiety and depression of elderly. Iranian Journal of Ageing. 2009; 4(11).

[35] Mirabzadeh A, Dolatian M, Forouzan AS, et al. Path analysis associations between perceived social support, stressful life events and other psychosocial risk factors during pregnancy and preterm delivery. Iranian Red Crescent Medical Journal. 2013; 15(6): 507. PMID:24349750. http://dx.doi.org/10.5812/ircmj.11271 